\title{
Development of an experimental model of neurocysticercosis-induced hydrocephalus. Pilot study ${ }^{1}$
}

\author{
Pedro Tadao Hamamoto Filho', Marco Antônio Zanini' ${ }^{I I}$, Fabio Pires Botta ${ }^{\mathrm{III}}$, Marianna Vaz Rodrigues ${ }^{\mathrm{IV}}$, Rodrigo Bazan ${ }^{\mathrm{V}}$, Luiz \\ Carlos Vulcano ${ }^{\mathrm{VI}}$, Germano Francisco Biondi ${ }^{\mathrm{VII}}$
}

DOI: http://dx.doi.org/10.1590/S0102-865020150120000005

IFellow Master degree, Postgraduate Program in General Basis of Surgery, Botucatu Medical School, Universidade Estadual Paulista (UNESP), Botucatu-SP, Brazil. Acquisition and interpretation of data, technical procedures, manuscript preparation.

IIAssistant Professor, Department of Neurology, Psychology and Psychiatry, Botucatu Medical School, UNESP, Botucatu-SP, Brazil. Conception, design, intellectual and scientific content of the study; critical revision.

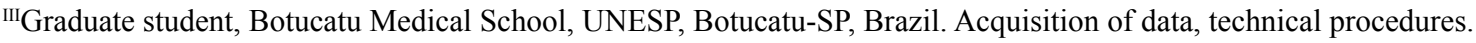

${ }^{\mathrm{IV}} \mathrm{PhD}$, Department of Microbiology and Immunology, Institute of Biosciences, UNESP, Botucatu-SP, Brazil. Technical procedures, critical revision.

vAssistant Professor, Department of Neurology, Psychology and Psychiatry, Botucatu Medical School, UNESP, Botucatu-SP, Brazil. Critical revision.

${ }^{\mathrm{VI} F u l l}$ Professor, Department of Animal Reproduction and Veterinary Radiology, School of Veterinary Medicine and Animal Science, UNESP, BotucatuSP, Brazil. Interpretation of data, technical procedures, critical revision.

VIIFull Professor, Department of Veterinary Hygiene ad Public Health, School of Veterinary Medicine and Animal Science, UNESP, Botucatu-SP, Brazil. Technical procedures, critical revision.

\begin{abstract}
PURPOSE: To develop an experimental model of neurocysticercosis-induced hydrocephalus

METHODS: There were used 17 rats. Ten animals were inoculated with Taenia crassiceps cysts into the subarachnoid. Five animals were injected with $0.1 \mathrm{ml}$ of $25 \%$ kaolin (a standard solution for the development of experimental hydrocephalus) and two animals were injected with saline. Magnetic resonance imaging (MRI) was used to evaluate enlargement of the ventricles after one or three months of inoculation. Volumetric study was used to quantify the ventricle enlargement.

RESULTS: Seven of the 10 animals in the cyst group developed hydrocephalus, two of them within one month and five within three months after inoculation. Three of the five animals in the kaolin group had hydrocephalus and none in the saline group. Ventricle volumes were significantly higher in the 3-months MRI cyst subgroup than in the 1-month cyst subgroup. Differences between cyst subgroups and kaolin group did not reach statistical significance.

CONCLUSION: The developed model may reproduce the human condition of neurocysticercosis-related hydrocephalus, which exhibits a slowly progressive chronic course.
\end{abstract}

Key words: Neurocysticercosis. Hydrocephalus. Magnetic Resonance Imaging. Cerebrospinal Fluid. Rats. 


\section{Introduction}

Neurocysticercosis is the most common parasitic disease of the central nervous system. The clinical manifestations of neurocysticercosis are pleomorphic and depend on the number and developmental stage of the parasite and site affected, as well as on the immune response of the patient ${ }^{1,2}$. Cysts located in the basal cisterns and ventricles are associated with a more aggressive course. This condition is called extraparenchymal neurocysticercosis and can manifest as vasculitis, cysticercal meningitis, hydrocephalus and intracranial hypertension ${ }^{3,4}$.

Hydrocephalus is the result of chronic inflammatory arachnoiditis or mechanical obstruction of cerebrospinal fluid (CSF) flow ${ }^{4-6}$. The conditions occurs in about $30 \%$ of patients with neurocysticercosis and is associated with high rates of mortality ${ }^{4,7}$. The treatment of choice in these cases is surgery consisting of the microsurgical removal of cysts, when possible, or CSF shunts ${ }^{4}$. Although CSF shunts are the most widely employed procedure, they are associated with several complications such as infection and dysfunction, which require reoperations ${ }^{8,9}$. Thus, hydrocephalus is the malignant form of neurocysticercosis par excellence. Several studies of experimental neurocysticercosis focusing on immune responses and on parasite-host interactions have been published ${ }^{10,11}$ but none of them focused on hydrocephalus.

The complexity of the relation between host and parasite, modulated by use of corticoids in clinical practice, make it difficult to fully understand the pathophysiologic mechanisms responsible for determining hydrocephalus in neurocysticercosis. This way, an animal model to help understand the inflammatory response is critical.

The aim of the present study was to develop an experimental model of neurocysticercosis-induced hydrocephalus in an attempt to reproduce a common and challenging clinical problem in the laboratory.

\section{Methods}

The animals were handled according to ethical guidelines and current legislation. The board of the local Ethics Committee on Animal Use approved the project.

Seventeen adult Wistar rats (Rattus norvegicus) weighing 150 to $250 \mathrm{~g}$ were used. The animals were kept under adequate sanitary conditions in a temperature-controlled room $\left(21^{\circ} \mathrm{C}\right)$ under light-dark control. Food and water were available ad libitum.

\section{Parasites and inoculation}

Taenia crassiceps cysts were maintained in the peritoneal cavity of mice (Mus musculus). After aseptic removal, the cysts were injected into the cisterns of rats by suboccipital puncture with a $25 \mathrm{G}$ needle. All animals were submitted to general anesthesia by intraperitoneal injection of a mixture of ketamine $(100 \mathrm{mg} / \mathrm{ml})$ and xylazine $(20 \mathrm{mg} / \mathrm{ml})$ at a dose of $0.1 \mathrm{ml} / \mathrm{kg}$.

\section{Experimental groups}

The animals were divided into three groups: cyst group (subarachnoid injection of 50 cysts, $\mathrm{n}=10$ ), kaolin group (subarachnoid injection of $0.1 \mathrm{ml}$ of $25 \%$ kaolin - hydrated aluminum silicate, a standard solution to induce experimental hydrocephalus ${ }^{12,13} ; n=5$ ), and sham group (subarachnoid injection of $0.1 \mathrm{ml}$ of $0.9 \%$ saline, $\mathrm{n}=2$ ).

\section{Radiologic assessment}

Magnetic resonance imaging (MRI) using a $0.25 \mathrm{~T}$ equipment (Esaote model Vet-MR) was performed to verify the development of hydrocephalus. The protocol consisted of T2weighted gradient echo acquisitions (0.6-mm thickness; $\mathrm{T}$ eco $=5 \mathrm{~ms}$; $\mathrm{T}$ repetition $=10 \mathrm{~ms})$. MRI was performed within one month after the procedure in the kaolin and sham groups and also in five animals of the cyst group. The other five animals of the cyst group were submitted to MRI three months after inoculation. The animals were euthanized after MRI. Ventricle volume was assessed using the ITK-SNAP software (version 3.0.0, USA) to determine the severity of hydrocephalus.

\section{Statistical analysis}

The statistical analysis was performed using the softwares SPSS version 21.0, R version 2.11.0 and GraphPad version 5.0. For comparison of ventricle volume we used the Kruskal-Wallis nonparametric test followed by the Dunn test for multiple comparisons. Differences were considered statistically significant if $\mathrm{p}<0.05$. 


\section{Results}

In the kaolin group, three of the five animals developed hydrocephalus (Figure 1A). Volumetric analysis in this group showed a median ventricle volume of $24.4 \mathrm{~mm}^{3}$. In the cyst group, seven of the ten animals developed hydrocephalus (Figure $1 \mathrm{~B}$ and $1 \mathrm{C}$ ), which was more evident in the subgroup of animals that underwent MRI three months after inoculation (5/5 animals, median ventricle volume $=120 \mathrm{~mm}^{3}$ ) than in the subgroup submitted to MRI 1 month after inoculation (2/5 animals, median ventricle volume $=4.8 \mathrm{~mm}^{3}$ ). No animal of the sham group had hydrocephalus (Figure 1D; mean ventricle volume $=3.0 \mathrm{~mm}^{3}$ ). Ventricle volumes were significantly higher in the three-months MRI cyst subgroup than in the 1-month cyst subgroup. Differences between cyst subgroups and kaolin group did not reach statistical significance $(p>0.05)$. The data are summarized in Table 1 . We did not observe any changes on neurobehavioural patterns of cystinoculated animals through the experimental course period.

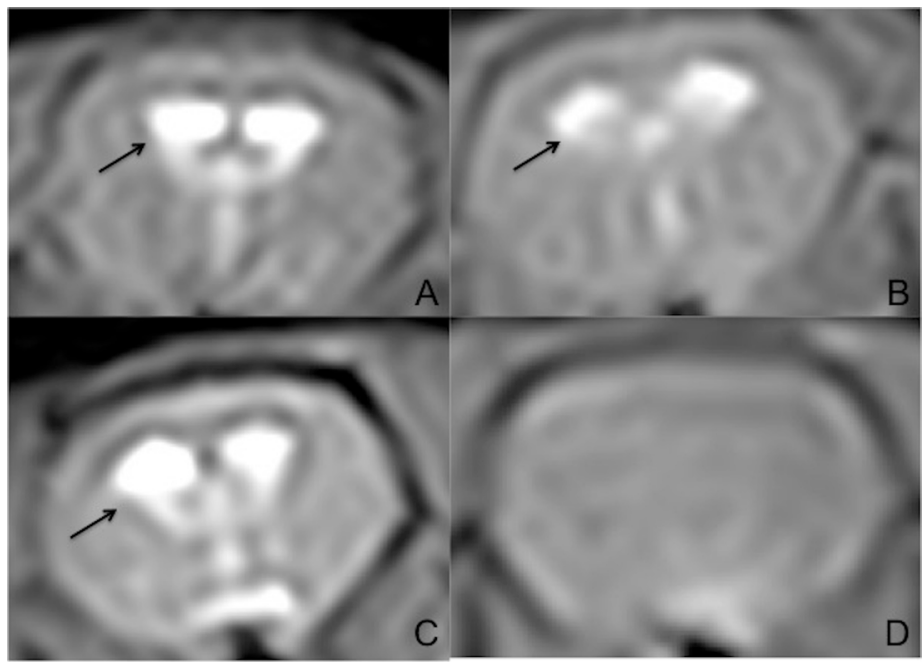

FIGURE 1 - T2-weighted gradient echo MRI scans obtained for each experimental group. A: kaolin group; B: cyst group, MRI performed 1 month after inoculation; $\mathbf{C}$ : cyst group, MRI performed 3 months after inoculation; D: sham group. The selected images are from equivalent head positions. Enlarged ventricles are pointed with arrows. A and $\mathrm{C}$ show definite ventricle enlargement, whereas B shows mild ventricle enlargement. Ventricle is not visible on $\mathrm{D}$, as the animal is not hydrocephalic

TABLE 1 - Number of successful inductions of hydrocephalus and median ventricle volume in the experimental groups.

\begin{tabular}{|c|c|c|c|c|}
\hline & \multirow[b]{2}{*}{$\begin{array}{l}\text { Kaolin group } \\
\quad(\mathrm{n}=5)\end{array}$} & \multicolumn{2}{|c|}{ Cyst group } & \multirow[b]{2}{*}{$\begin{array}{l}\text { Sham group } \\
\quad(\mathrm{n}=2)\end{array}$} \\
\hline & & $\begin{array}{l}1 \text { month MRI } \\
\quad(n=5)\end{array}$ & $\begin{array}{c}3 \text { months MRI } \\
(\mathrm{n}=5)\end{array}$ & \\
\hline Number of hydrocephalic animals & 3 & 2 & 5 & 0 \\
\hline $\begin{array}{c}\text { Median ventricle volume }\left(\mathrm{mm}^{3}\right) \\
\text { Range }\left(\mathrm{mm}^{3}\right)\end{array}$ & $\begin{array}{c}24.4 \\
(1.0-692.0)\end{array}$ & $\begin{array}{c}4.8^{*} \\
(0.4-40.2)\end{array}$ & $\begin{array}{c}120.0^{*} \\
(49.0-437.0)\end{array}$ & $\begin{array}{c}\text { Mean: } 3.0 \\
(1.68-4.35)\end{array}$ \\
\hline
\end{tabular}

*Ventricle volumes were significantly higher in the 3 -months MRI subgroup than in the 1-month MRI subgroup ( $\mathrm{p}<0.05)$. The cutoff value of $5.0 \mathrm{~mm}^{3}$ was set to consider a normal ventricle volume. ${ }^{14}$

\section{Discussion}

Human studies on the inflammatory response to neurocysticercosis are very limited because of the chronic progression of the disease, its different developmental stages, and the influence of administered corticosteroids ${ }^{10}$.

Since Taenia solium, the tapeworm that causes human neurocysticercosis, does not infect rodents in experimental assays $^{11}$, alternative parasites have been used. Taenia crassiceps is a tapeworm related to $T$. solium. Its definitive hosts are foxes, wolves and dogs, and its intermediate hosts are wild rodents ${ }^{15}$. The biological cycle of $T$. crassiceps resembles that of $T$. solium, a fact rendering it a useful alternative. Another parasite widely used as a model of experimental neurocysticercosis is Mesocestoides corti; however, this parasite tends to invade the brain parenchyma and to replicate in the CNS, so it does not exactly reproduce the biological behavior of T. solium in the $\mathrm{CNS}^{11}$.

With respect to experimental neurocysticercosis, studies from the group of Teale ${ }^{10,16}$ have focused on the type of cellmediated immune response and on the mechanisms responsible for leukocyte migration across the blood-brain barrier and ependyma. The authors found that the immune response of mice to neurocysticercosis is mediated by gamma delta $\mathrm{T}$ lymphocytes guided by a Th1 pattern of response. ${ }^{10}$ Furthermore, junctional complex proteins and matrix metalloproteinases were found to be directly involved in leukocyte infiltration ${ }^{16}$.

Matos-Silva et al. ${ }^{17}$ analyzed general inflammatory responses in a mouse model of encephalitis after inoculation of $T$. crassiceps. The authors observed the occurrence of ventriculomegaly, but this finding was casual and was probably 
due to mechanical obstruction of the lateral ventricle since the ventriculomegaly observed was asymmetrical, shifting the midline.

Hydrocephalus in experimental neurocysticercosis has so far not been well documented. This may be due to the fact that all previously published experimental studies of neurocysticercosis injected cysts into the convex brain surface through a burr hole, which tends to mimic human parenchymal neurocysticercosis. We believed that it was necessary to inject the cysts into the CSF compartments in order to reproduce human extraparenchymal neurocysticercosis.

One may argue that our hydrocephalus results were due to mechanical obstruction of CSF outflow from the fourth ventricle to the subarachnoid space - it is, an obstructive hydrocephalus. We cannot rule out this possibility. However the fact that hydrocephalus was observed in only 2/5 animals within 1 month and in all animals after three months points to the possibility of a slowly progressing inflammatory reaction resulting in elevated resistance to CSF absorption, which favors the occurrence of arachnoiditis leading to hydrocephalus. This may reproduce the human condition of neurocysticercosis-related hydrocephalus, which exhibits an "arrested" course (a hydrocephalus that progresses very gradually and seems to be compensated $)^{18}$.

The kaolin model has permitted significant advances in the understanding of the pathophysiology of hydrocephalus: ependymal disruption, periventricular edema, reactive astrogliosis, axon damage, corpus callosum flattening, myelin disintegration, and neuronal degeneration ${ }^{13,19,20}$. Recently, aquaporin-4 and its upregulation in hydrocephalus have been suggested as an alternative pathway for CSF absorption and partial compensation of CSF imbalance ${ }^{21-23}$. However in the kaolin-induced hydrocephalus model it is difficult to achieve control of the severity of hydrocephalus ${ }^{24}$, as we have observed in our results from the kaolin group. Additionally, the classic kaolin model induces rapid enlargement of the brain ventricles, which differs from the "arrested" course of many patients seen in clinical practice. In this classic model, the animals have severe clinical manifestations such as loss of weight and severe neurobehavioural changes $^{25}$. To study an arrested course of hydrocephalus, Del Bigio et al. ${ }^{18}$ proposed a model of low-dose kaolin injection into immature rats. The authors achieved slow ventricle enlargement associated with pathological alterations similar to those seen in humans. However, another model of adult-onset slow progressive hydrocephalus is needed. Our model may have accomplished this goal, with the advantage of keeping animals healthy without noticeable neurobehavioural changes. Weekly repeated MRI scans of animals with neurocysticercosis-induced hydrocephalus could confirm if our model reproduces the arrested course of many patients. Also the use of contrast enhancement on MRI could highlight inflammatory reactions within CSF compartments. In the same way, analysis of CSF contents could demonstrate inflammatory changes.

Future investigation of our model will differentiate whether hydrocephalus is due to mechanical obstruction or to inflammatory responses in the basal cisterns, although both events occur in clinical practice. Finally, we will study histological and immunological features elicited by the presence of cysts in the CSF compartments.

\section{Conclusion}

The developed model may reproduce the human condition of neurocysticercosis-related hydrocephalus, which exhibits a slowly progressive chronic course.

\section{References}

1. Takayanagui OM, Leite JP. Neurocysticercosis. Rev Soc Bras Med Trop. 2001;34:283-90. doi: 10.1590/S0037-86822010000600009.

2. Sotelo J. Clinical manifestations, diagnosis, and treatment of neurocysticercosis. Curr Neurol Neurosci Rep. 2011;11:529-35. doi: 10.1007/s11910-011-0226-7.

3. Coyle CM. Neurocysticercosis: an update. Curr Infect Dis Rep. 2014;16:437. doi: 10.1007/s11908-014-0437-6.

4. Proaño JV, Torres-Corzo J, Rodrígues-Dalla Vecchia R. GuizarSahagun G, Rangel-Castilla L. Intraventricular and subarachnoidal basal cisterns neurocysticercosis: a comparative srtudy between traditional treatment versus neuroendoscopic surgery. Childs Nerv Syst. 2009;25:1467-5. doi: 10.1007/s00381-009-0933-4.

5. Matushita H, Pinto FCG, Cardeal DD, Teixeira MJ. Hydrocephalus in neurocysticercosis. Childs Nerv Syst. 2011;27:1709-21. doi: 10.1007/s00381-011-1500-3.

6. Mahale RR, Mehta A, Rangasetty S. Extraparenchymal (racemose) neurocysticercosis and its multitude manifestations: a comprehensive review. J Clin Neurol. 2015;11:e3. PMID: 26022457.

7. White Jr AC. Neurocysticercosis: a major cause of neurological disease worldwide. Clin Infect Dis. 1997;24:101-3. PMID: 9114131.

8. Kelley R, Duong DH, Locke GE. Characteristics of ventricular shunt malfunctions among patients with neurocysticercosis. Neurosurgery. 2002;50:757-62. PMID: 11904026.

9. Agapejev S, Souza AFP, Bazan R, Faleiros ATS. Clinical and evolutive aspects of hydrocephalus in neurocysticercosis. Arq Neuropsiquiatr. 2007;65:674-80. doi: 10.1590/S0004-282X2007000400025.

10. Cardona AE, Restrepo BI, Jaramillo JM, Teale JM. Development of an animal model for neurocysticercosis: imune response is characterized by a predominance of $\gamma \delta \mathrm{T}$ cells. J Immunol. 1999;162:995-1002. PMID: 9916725.

11. Alvarez JI, Mishra BB, Gundra UM, Mishra PK, Teale JM. Mesocestoides corti intracranial infection as a murine model for neurocysticercosis. Parasitology. 2010;137:359-72. doi: 10.1017/ S0031182009991971.

12. Basati S, Desai B, Alaraj A, Charbel F, Linninger A. Cerebrospinal 
fluid volume measurements in hydrocephalic rats. J Neurosurg Pediatr. 2012;10:347-54. doi: 10.3171/2012.6.PEDS11457.

13. Del Bigio MR. Neuropathological changes caused by hydrocephalus. Acta Neuropathol. 1993;85:573-85. PMID: 8337936.

14. Harris NG, Jones HC, Williams CR. MR imaging for measurements of ventricles and cerebral cortex in postnatal rats (H-TX Strain) with progressive inherited hydrocephalus. Exp Neurol. 1992;118:1-6. PMID: 1397170.

15. Willms K, Zurabian R. Taenia crassiceps: in vivo and in vitro models. Parasitology. 2010;137:335-46. doi: 10.1017/S0031182009991442.

16. Alvarez JI, Teale JM. Multiple expression of matrix metaloproteinases in murine neurocysticercosis: implications for leukocyte migration through multiple central nervous system barriers. Brain Res. 2008;1214:145-58. doi: 10.1016/j.brainres.2008.03.036.

17. Matos-Silva H, Reciputti BP, de Paula EC, Oliveira AL, Moura VBL, Vinaud MC, Oliveira MAP, Lino-Júnior RS. Experimental encephalitis caused by Taenia crassiceps cysticerci in mice. Arq Neuropsiquiatr. 2012;70:287-92. doi: 10.1590/S0004282X2012005000010.

18. Del Bigio MR, Wilson MJ, Enno T. Chronic hydrocephalus in rats and humans: white matter loss and behavior changes. Ann Neurol. 2003;53:337-46. doi: 10.1002/ana.10453.

19. Del Bigio MR, Zhang YW. Cell death, axonal damage, and cell birth in the immature rat brain following induction of hydrocephalus. Exp Neurol. 1998; 154:157-69. PMID: 9875277.

20. Khan OH, Enno TL, Del Bigio MR. Brain damage in neonatal rats following kaolin induction of hydrocephalus. Exp Neurol. 2006;200:311-20.

21. Bloch O, Auguste KI, Manley GT, Verkman AS. Accelerated progression of kaolin-induced hydrocephalus in aquaporin-4deficient mice. J Cereb Blood Flow Metabol. 2006;26:1527-37. doi: 10.1038/sj.jcbfm.9600306.

22. Brian OK, Tom P, Wang D. Aquaporins: relevance to cerebrospinal fluid physiology and therapeutic potential in hydrocephalus. Cerebrospinal Fluid Res. 2010;7:15. doi: 10.1186/1743-8454-7-15.

23. Skjolding AD, Rowland IJ, Sogaard LV, Praetorius J, Penkowa M, Juhler M. Hydrocephalus induces dynamics spatiotemporal regulation of aquaporin-4 expression in the rat brain. Cerebrospinal Fluid Res. 2010;7:20. doi: 10.1186/1743-8454-7-20.
24. Shaolin Z, Zhanxiang W, Hao X, Feifei Z, Caiquan H, Donghan C, Jianfeng B, Feng L, Shanghang S. Hydrocephalus induced via intraventricular kaolin injection in adult rats. Folia Neuropathol. 2015;53:60-8. doi: 10.5114/fn.2015.49975.

25. Olopade FE, Shokunbi MT, Sirén AL. The relationship between ventricular dilatation, neuropathological and neurobehavioural changes in hydrocephalic rats. Fluids Barriers CNS. 2012;9:19. doi: 10.1186/2045-8118-9-19.

\section{Acknowledgements}

To Dr. Diego Generoso for helping with animal procedures, Mr. Heraldo André Catalan Rosa for the support on magnetic resonance imaging acquisition, and Mr. Hélio Rubens de Carvalho Nunes for statistical analysis.

\section{Correspondence:}

Marco Antônio Zanini

Departamento de Neurologia, Psicologia e Psiquiatria-UNESP

Distrito de Rubião Jr. s/n.

18.618-970 Botucatu - SP Brasil

Tel.: (55 14)3880-1220

mzanini@fmb.unesp.br

Received: Aug 07, 2015

Review: Oct 11, 2015

Accepted: Nov 13, 2015

Conflict of interest: none

Financial source: none

${ }^{1}$ Research performed at Experimental Research Unit, Botucatu Medical School, Universidade Estadual Paulista (UNESP), Brazil. Part of Master degree thesis, Postgraduate Program in General Basis of Surgery, UNESP. Tutor: Marco Antônio Zanini. 